\title{
Reference Equation for the Six-Minute Walk Test in Brazilian Patients with Obesity
}

\author{
José Carlos do Vale Quaresma, João Regis Ivar Carneiro, ${ }^{(1)}$ Norma Ferreira Marschhausen, ${ }^{(1)}$ Gustavo Gavina \\ da Cruz, ${ }^{(1)}$ José Fernandes Filho, ${ }^{(1)}$ Ronir Raggio Luiz \\ Universidade Federal do Rio de Janeiro, Rio de Janeiro, RJ - Brazil.
}

\section{Abstract}

Background: Obesity has repercussions on functional capacity (FC). The six-minute walk test (6MWT) is a useful tool for assessing submaximal FC, and the distance reached at 6 minutes of walking (D6MW) is a relevant prognostic marker.

Objective: This paper aims to establish a reference equation for the distance predicted in $6 \mathrm{MWT}$ in obese Brazilian subjects.

Methods: This study included 460 patients (306 women), with a body mass index (BMI) $>30 \mathrm{~kg} / \mathrm{m}^{2}, 71 \%(328)$ of whom presented a grade III obesity (BMI $\geq 40 \mathrm{Kg} / \mathrm{m}^{2}$ ) and were evaluated with $6 \mathrm{MWT}$. Heart rate, blood pressure, oxygen saturation and Borg scale perception of effort were recorded before and after the 6MWT. For statistical analysis, Kolmogorov-Smirnov tests, an unpaired T-Test, Pearson's correlation, and multiple linear regression were used, together with a significance level set at $\mathrm{p}<0.05$.

Results: Gender, age, and BMI were significantly correlated with D6MW and were identified by multiple linear regression as the best predictors of the D6MW. Together, they explain $48.7 \%$ of the D6MW variance for obese Brazilian subjects. Based on these findings, an equation was proposed - D6MW $=930.138+(27.130 \times$ Genderfemales = 0 ; males $=1)-\left(5.550 \times \mathrm{BMI} \mathrm{kg} / \mathrm{m}^{2}\right)-(4.442 \times$ Age years $)$. When the average of the D6MW obtained with the above equation was compared to the average calculated with the equations described in medical literature for healthy and obese individuals, the latter tended to overestimate the D6MW.

Conclusion: The proposed reference equation exhibited better assessment of FC in obese Brazilian patients, providing proper subsidies for the follow up ofinterventions in this population.. (Int J Cardiovasc Sci. 2021; 34(3):307-314)

Keywords: 6-minute walk test, Obesity, Exercise tolerance.

\section{Introduction}

Obesity is a multifactorial condition that causes chronic deleterious implications on health and affects one's quality of life. It is recognized as an important cardiovascular risk factor which contributes to the reduction of cardiopulmonary functional capacity and exercise tolerance not only because of decreased skeletal muscle strength and elevated metabolic cost, but also because of progressive gait inefficiency. ${ }^{1,2}$

In Brazil, an increase in the prevalence of overweight and obese individuals has been observed in the last decade. ${ }^{1,3}$ In a recent report published by the Ministry of Health, VIGITEL Brasil 2016, ${ }^{4}$ it was stated that more than half of the population is overweight and that $18.9 \%$ of Brazilians are obese. These statistics show an increase of $60 \%$ in obesity taxes over the last 10 years, which contributes to a growth in hypertension (14.2\%) and diabetes $(61.8 \%)$ in the same period.

The six-minute walk test (6MWT) is a useful tool in the assessment of functional capacity and of the response to the demands required in daily life activities. In the last two decades, especially after the American Thoracic Society (ATS) published a guideline for the $6 \mathrm{MWT}$, reference 
equations for the distance predicted in the test have been indicated for different populations, both for healthy individuals and for patients with several chronic diseases. ${ }^{5-8}$

In 2009, Iwama et al., 9 proposed a reference equation for healthy Brazilian subjects. In 2011, Soares ${ }^{10}$ also presented a reference equation for healthy adults in Brazil, taking into account the body mass index (BMI) in their composition. In 2013, based on a multicentric study, Britto et al. ${ }^{11}$ published reference equations for the Brazilian population, which illustrates the growing interest in the 6MWT in our context.

The use of the 6MWT for the evaluation of obese patients has recently been observed, as shown in different already published studies. ${ }^{12-15}$ Thus, this study aims to establish a reference equation for the distance predicted in 6MWT in obese Brazilian patients.

\section{Methods}

The sample size was defined by convenience, patients were recruited according to their admission to the Multidisciplinary Program for the Treatment of Obesity and Bariatric Surgery (PROCIBA) at the Clementino Fraga Filho University Hospital of the Federal University of Rio de Janeiro (HUCFF-UFRJ - Brazil) between August 2007 and August 2017. All patients had 6 or more years of schooling and signed a Free and Informed Consent Form. This study was approved by the UFRJ Research Ethics Committee (CEP-HUCFF-CAAE, logged under project number 1041.0.197.000-05).

Patients with unstable angina, myocardial infarction, cardiac arrhythmias, heart rate (HR) greater than 120 beats per minute at rest, blood presure (BP) $\geq 160 / 100$ mmhg at rest, peripheral oxygen saturation lower than $95 \%$ at rest, neurological and /or orthopedic conditions capable of restricting gait were excluded.

Using a standardized technique, ${ }^{(16)}$ the patients' weight $(w)$ was obtained with a Filizola calibrated balance $(0.1$ $\mathrm{kg}$ of precision) when they were barefoot and wearing light clothes. The patients' height (h) was measured with a stadiometer ( $0.5 \mathrm{~cm}$ accuracy). Afterwards, their body mass index (BMI) was calculated using the following formula: $\mathrm{BMI}=\mathrm{w}(\mathrm{kg}) / \mathrm{h}\left(\mathrm{m}^{2}\right)$.

The 6MWT was applied to all participants in accordance with the "ATS Statement: Guidelines for the Six-minute Walk Test". ${ }^{16}$ Patients were advised to walk as fast as possible in a quiet and unobstructed hallway, 30 meters long, with each meter marked. Encouragement instructions were standardized and given every minute. The walk could be interrupted at any moment by the patient or the examiner in the presence of chest pain, intolerable dyspnea, dizziness, pallor, sweating, cramps, imbalance, and physical exhaustion. Before and after the test, the patients' HR and peripheral oxygen saturation were recorded with a pulse oximeter (Onix II, Nonin Medical Inc., Plymouth, Minnesota). Their BP was measured with a cuff diameter corresponding to the group of patients under study, ${ }^{17}$ and their subjective perception of effort was graded according to the Borg scale. ${ }^{18}$ The distance reached at 6 minutes of walking (D6MW) was recorded and compared to predicted values based on three reference equations employed in other populations.

\section{Statistical Analysis}

Statistical analysis was performed with the usage of the IBM-SPSS Statistic 22 program. Statistical significance was set at $\mathrm{p}<0.05$. Data were presented as mean \pm standard deviation. Categorical variables were described using absolute and percentage values. To compare the means, an unpaired T-Test was used. From an initial universe of 510 patients, the Kolmogorov-Smirnov test identified a distribution pattern with discrete asymmetry. To determine the explanatory variables (demographic and anthropometric attributes) that are significantly and independently best associated with the result variable (D6MC), Pearson's correlation was conducted.

The bivariate association between age and BMI with D6MC respectively, as well as the $95 \%$ confidence interval (CI) lines for individual predicted values, are shown in Figures 1 and 2. The participants selected for our sample were between the lines of $95 \%$ CI. Therefore, 460 obese patients (306 women) remained with a BMI $\geq 30 \mathrm{~kg} / \mathrm{m}^{2}$, the majority $(71 \%)$ with grade III obesity (BMI> $\left.40 \mathrm{~kg} / \mathrm{m}^{2}\right){ }^{19}$

Seeking to build a multiple linear regression model, and understanding the need to obey the assumptions for its use, it can be concluded that, despite the discreet asymmetry, the residues of our model have an approximately normal distribution, as the sample size is large enough to accept the premise of normality. ${ }^{20}$

\section{Results}

The general characteristics of the 460 obese patients, 306 women (67\%), are presented in Table 1. A significant difference was observed between men and women for age and D6MC, with $\mathrm{p}<0.05$, as well as for weight, height, 

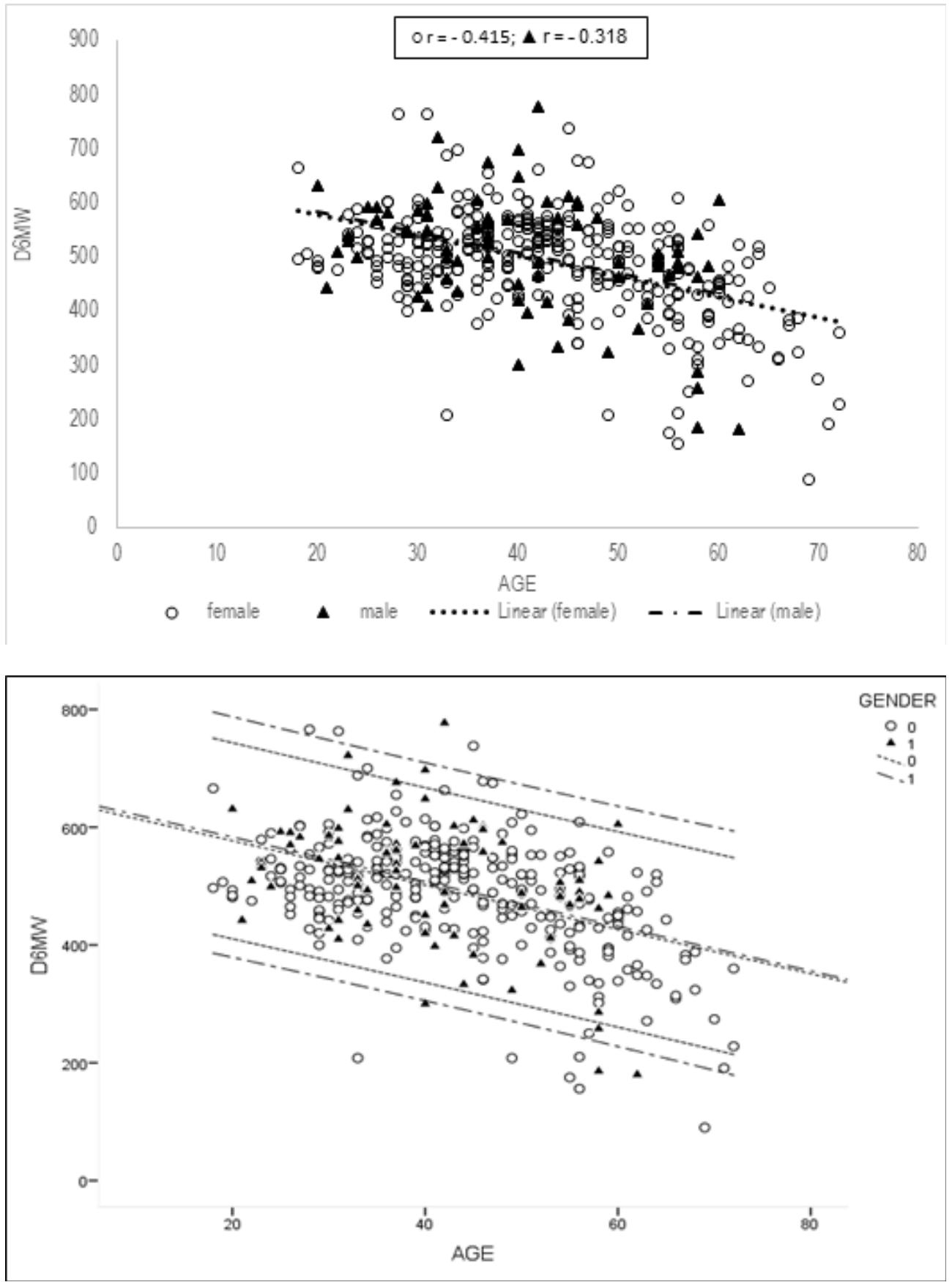

Figure 1 (A) - Correlation between distance reached at 6 minutes of walking (D6MW) and age. (B) Scattergram with lines of $95 \% \mathrm{CI}$ for individual predictive value.

and BMI, with $\mathrm{p}<0.001$. Taking the entire group into consideration, the D6MW had a significant correlation with sex $(r=0.102, p<0.029)$, age $(r=-0.387, p<0.001)$, weight $(r=-0.312, p<0.001)$, height $(r=0.163, p<0.001)$, and BMI $(\mathrm{r}=-0.464, \mathrm{p}<0.001)$. Therefore, the D6MW is explained $1 \%$ due to sex, $14.9 \%$ to age, $9.7 \%$ to weight, $2.6 \%$ to height, and $21.5 \%$ to BMI.
For multiple linear regression, the best model adjusted for the D6MW predictor was that using the variables of gender, age, and BMI, which together explain $48.7 \%$ of the total D6MW variance (Table 2). The equation proposed as reference for Brazilian subjects with obesity is as follows: D6MW $=930.138+(27.130 \times$ Genderfemales $=0$; males $=$ 1) - $(5.550 \times$ BMI kg / m²) - (4.442 $\times$ Age years $)$. 

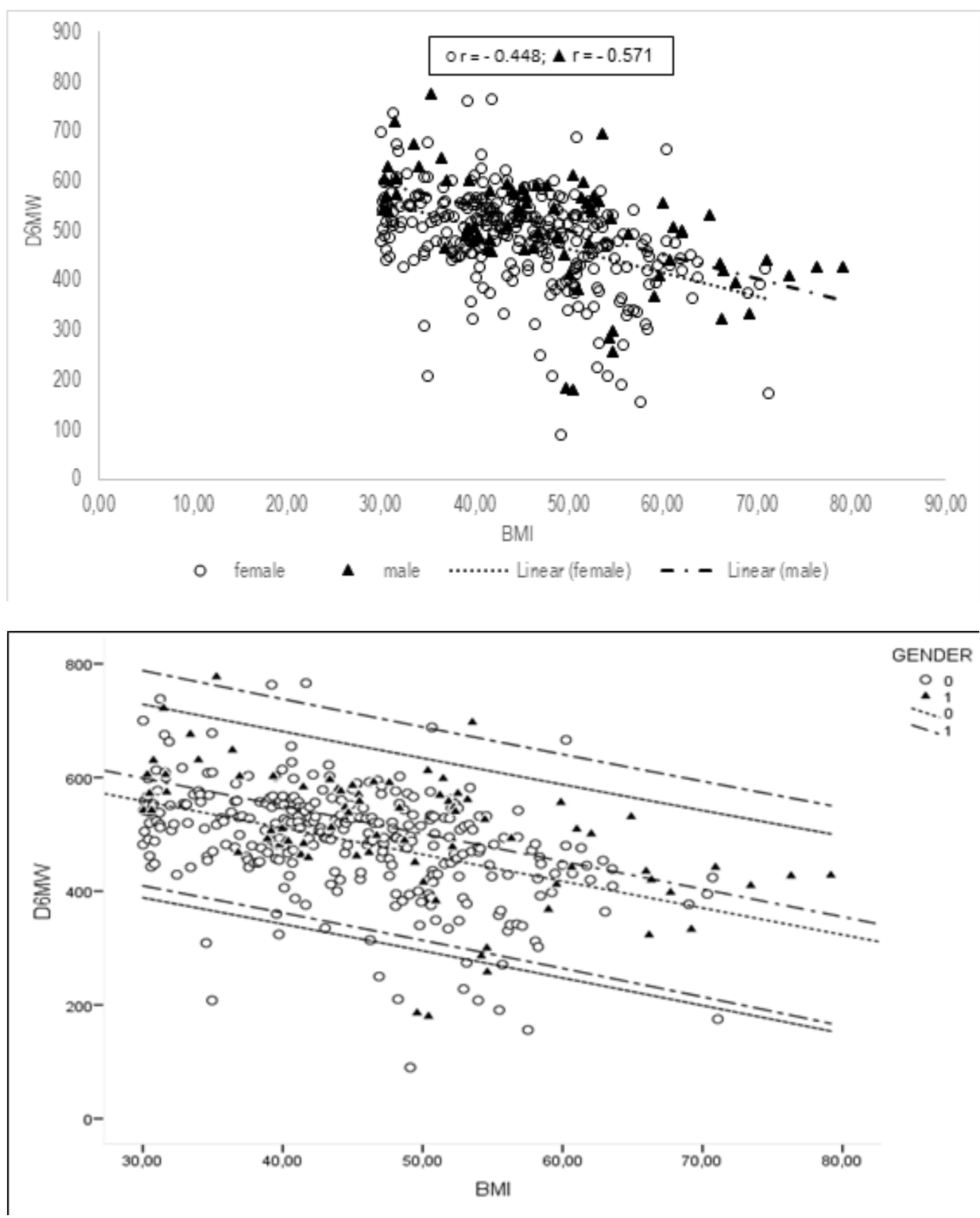

Figure 2 (A) - Correlation between distance reached at 6 minutes of walking (D6MW) and body mass index (BMI). (B) Scattergram with lines of $95 \%$ CI for individual predictive value.

When we compared the mean of the D6MW for the whole group, obtained with the above equation, to the mean calculated by the Enright ${ }^{5}$ and Iwama ${ }^{9}$ equations for healthy individuals, and to the mean calculated by the Capodaglio equation ${ }^{13}$ for obese individuals, it was observed that these equations tend to overestimate the values for D6MW (Figure 3).

\section{Discussion}

Functional capacity to exercise is an important marker of mortality and morbidity. In obese patients, walking requires greater metabolic and cardiopulmonary demand. Moreover, the additional musculoskeletal dysfunction due to joint overload and osteoarthrosis 
Table 1 - General characteristics

\begin{tabular}{|c|c|c|}
\hline \multirow{2}{*}{ Characteristics } & Male & Female \\
\hline & $(\mathrm{n}=154)$ & $(\mathrm{n}=306)$ \\
\hline Obesity Grade I, n (\%) & $18(12)$ & $52(17)$ \\
\hline Obesity Grade II, n (\%) & $18(12)$ & $44(14)$ \\
\hline Obesity Grade III, n (\%) & $118(76)$ & $210(69)$ \\
\hline \multicolumn{3}{|l|}{ Age (years) } \\
\hline Mean \pm SD & $40 \pm 11.2$ & $43 \pm 12.1$ \\
\hline \multicolumn{3}{|l|}{ Weight (kg) } \\
\hline Mean \pm SD & $149.6 \pm 37.8$ & $116.7 \pm 26.0$ \\
\hline \multicolumn{3}{|l|}{ Height (m) } \\
\hline Mean \pm SD & $1.75 \pm 0.07$ & $1.61 \pm 0.07$ \\
\hline \multicolumn{3}{|l|}{$\mathrm{BMI}\left(\mathrm{kg} / \mathrm{m}^{2}\right)$} \\
\hline Mean \pm SD & $48.99 \pm 11.61$ & $44.78 \pm 8.88$ \\
\hline \multicolumn{3}{|l|}{ D6MW (m) } \\
\hline Mean \pm SD & $506 \pm 110$ & $489 \pm 95.4$ \\
\hline
\end{tabular}

Table 2 - Predictive model for the distance reached in the 6-minute walk test in obese Brasilian subjects

\begin{tabular}{|c|c|c|c|c|c|}
\hline \multirow{2}{*}{ Variable } & \multirow{2}{*}{ Coefficient } & \multirow{2}{*}{ SEM } & \multirow{2}{*}{ p } & \multicolumn{2}{|c|}{$95 \% \mathrm{CI}$} \\
\hline & & & & Minimum & Maximum \\
\hline Constant & 930.138 & 21.641 & $<0.001$ & 887.609 & 972.667 \\
\hline Gender & 27.130 & 7.301 & $<0.001$ & 12.782 & 41.479 \\
\hline AGE (years) & -4.442 & 0.289 & $<0.001$ & -5.009 & -3.874 \\
\hline BMI $\left(\mathrm{kg} / \mathrm{m}^{2}\right)$ & -5.550 & 0.345 & $<0.001$ & -6.228 & -4.872 \\
\hline
\end{tabular}

(knees, ankles and hip), associated with eventual loss of muscle mass, can be factors that contribute to a lower performance in walking. ${ }^{2,6,21}$ As 6MWT is easy to apply, has a low cost, is safe, and is easily correlated with the activities of daily life, mostly at the submaximal level, it represents a relevant element in the evaluation of obese patients' functional capacity. Consequently, D6MW becomes a significant prognostic indicator. ${ }^{6,22}$
Previous studies have already described age, sex, weight, height, and BMI as variables capable of influencing D6MW. ${ }^{5,9,12,13,23,24}$ For obese individuals, especially those with BMI $\geq 40 \mathrm{~kg} / \mathrm{m} 2$, as already mentioned, musculoskeletal dysfunctions and loss of muscle mass are factors that have a considerable influence on D6MW, particularly with advancing age $^{2,25}$ (Figure 1). 


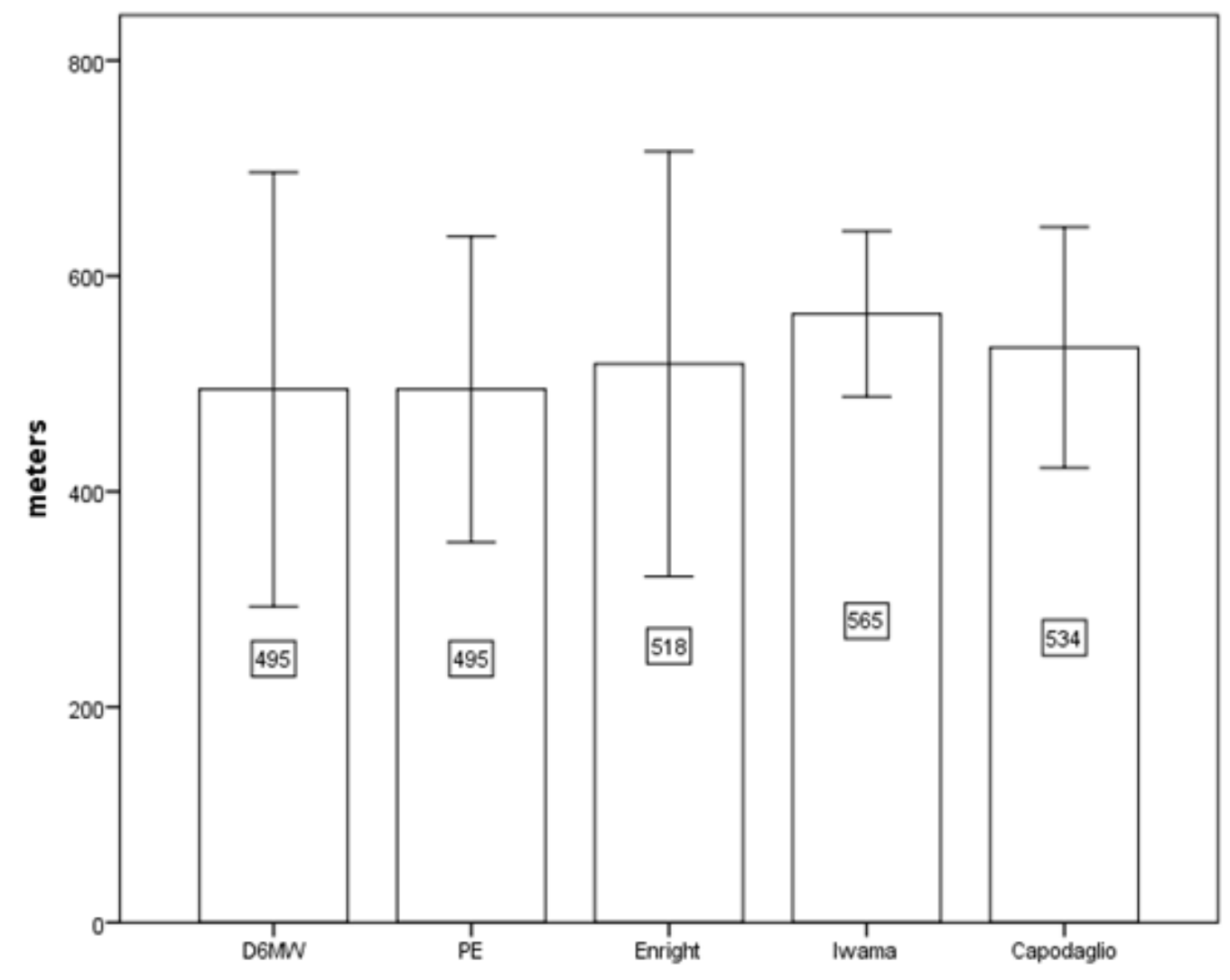

Figure 3 - Mean of the distance reached at 6 minutes of walking (D6MC), of the proposed equation (PE), and distances predicted by the equations present in the literature (see text).

The importance of BMI in the D6MW variance in a population of obese patients has been described in medical literature, ${ }^{12,15,21,26}$ despite the significant difference in BMI between the genders $(\mathrm{p}<0.001)$ found in our patient group, where the BMI was able to explain $32.6 \%$ for men and $20 \%$ for women of the D6MW results . It was observed that, for a growing value of BMI, there is a reduction of D6MC in both sexes (Figure 2).

In our study, for the whole group, age was able to explain $14.9 \%$ and BMI $21.5 \%$ of the results. Data slightly different from those previously obtained by Capodaglio with obese patients, ${ }^{13}$ where age explained $12.9 \%$ and BMI $24 \%$ of the D6MW results. This difference occurs because our population is older and with a smaller number of male subjects, who are proportionally heavier. However, our results were similar to Capodaglio's in relation to the total variance of the D6MW, explained by the three chosen variables (gender, age, and BMI), that is, $48 \%$ in Capodaglio's study and $48.7 \%$ in our investigation.
A greater number of variables introduced in the equation, as already pointed out by other authors, ${ }^{(14,}$ ${ }^{20)}$ could provide a better evaluation from a purely mathematical point of view. On the other hand, this study would lose in practicality, since a greater number of variables would lead to a greater complexity in the collection of data in an outpatient environment of basic health care.

Our study, does, however have some limitations. The sample was chosen for convenience, allowing for some selection bias. This study consists of patients with a predominance of grade III obesity, most of whom were female, who sought out bariatric surgery to treat their obesity. In addition, about $50 \%$ of the D6MC variance remains unexplained by our regression model. Caution should be taken when using the proposed equation for patients with different characteristics from our cohort. This study should also be repeated with a larger number of participants under the age of 40 and over 60 , and with grade I and II obesity. 


\section{Conclusion}

The reference equation proposed in this study shows a significant adjustment, when compared to the equations already described in the literature, and allows for a better estimate of the submaximal functional capacity of Brazilian patients with obesity, which provides better subsidies for monitoring the therapeutic interventions performed in this population.

\section{Potential Conflict of Interest}

No potential conflict of interest relevant to this article was reported.

\section{Sources of Funding}

There were no external funding sources for this study.

\section{Study Association}

This article is part of the thesis of Doctoral submitted by José Carlos do Vale Quaresma, from Universidade Federal do Rio de Janeiro.

\section{References}

1. Simão AF, Precoma DB, Andrade JP, Correa Filho H, Saraiva JF, Oliveira GM, et al. I Diretriz Brasileira de Prevenção Cardiovascular. Arq Bras Cardiol. 2013;101(6 Suppl 2):1-63.

2. Donini LM, Poggiogalle E, Mosca V, Pinto A, Brunani A, Capodaglio P. Disability affects the 6-minute walking distance in obese subjects (BMI $>40$ kg/m(2)). PLoS One. 2013;8(10):e75491.

3. Herdy AH, Lopez-Jiménez F, Terzic CP, Milani M, Stein R, Carvalho T, et al. South American Guidelines for Cardiovascular Disease Prevention and Rehabilitation. Arq Bras Cardiol. 2014;103(2 Suppl 1):1-31.

4. MinistériodaSaúde. VIGITEL BRASIL In: http://portalarquivos.saude. gov.br/images/pdf/2017/abril/17/Vigitel.pdf, editor. Brasilia, Brasil: Ministério da Saúde; 2016.

5. Enright PL, Sherrill DL. Reference equations for the six-minute walk in healthy adults. Am J Respir Crit Care Med. 1998;158(5 Pt 1):1384-7.

6. ATS Statement: Guidelines for the Six-Minute Walk Test. Am J Respir Crit Care Med. 2002;166(1):111-7.

7. Casanova C, Celli BR, Barria P, Casas A, Cote C, de Torres JP, et al. The 6-min walk distance in healthy subjects: reference standards from seven countries. Eur Respir J. 2011;37(1):150-6.

8. Dourado VZ. Equações de referência para o teste de caminhada de seis minutos em indivíduos saudáveis. Arq Bras Cardiol. 2011;96(6):e128-e38.

9. Iwama AM, Andrade GN, Shima P, Tanni SE, Godoy I, Dourado VZ. The six-minute walk test and body weight-walk distance product in healthy Brazilian subjects. Braz J Med Biol Res. 2009;42(11):1080-5.

10. Soares MR, Pereira CA. Six-minute walk test: reference values for healthy adults in Brazil. J Bras Pneumol. 2011;37(5):576-83.

11. Britto RR, Probst VS, Andrade AF, Samora GA, Hernandes NA, Marinho $\mathrm{PE}$, et al. Reference equations for the six-minute walk distance based on a Brazilian multicenter study. Braz J Phys Ther. 2013;17(6):556-63.

\section{Author Contributions}

Conception and design of the research: JCV Quaresma. Acquisition of data: JCV Quaresma, NF Marschhausen, GG Cruz. Analysis and interpretation of the data: JCV Quaresma, NF Marschhausen, GG Cruz, JRI Carneiro, J Fernandes Filho, RR Luiz. Statistical analysis: JCV Quaresma, RR Luiz. Writing of the manuscript: JCV Quaresma, NF Marschhausen, GG Cruz, JRI Carneiro, J Fernandes Filho, RR Luiz. Critical revision of the manuscript for intellectual content: JCV Quaresma, GG Cruz, JRI Carneiro, J Fernandes Filho, RR Luiz.

\section{Ethics Approval and Consent to Participate}

This study was approved by the Ethics Committee of the CEP-HUCFF under the protocol number 1041.0.197.000-05. All the procedures in this study were in accordance with the 1975 Helsinki Declaration, updated in 2013. Informed consent was obtained from all participants included in the study.

12. Larsson UE, Reynisdottir S. The six-minute walk test in outpatients with obesity: reproducibility and known group validity. Physiother Res Int. 2008;13(2):84-93.

13. Capodaglio P, De Souza SA, Parisio C, Precilios H, Vismara L, Cimolin $\mathrm{V}$, et al. Reference values for the 6-Min Walking Test in obese subjects. Disabil Rehabil. 2012;35(14):1199-203.

14. Donini LM, Poggiogalle E, Mosca V, Pinto A, Migliaccio S, Brunani A, et al. Critical review of the equations predicting 6-minute walking distance in obese subjects. Monaldi Archives for Chest Disease. 2015;81(1-2):745-52.

15. Beriault K, Carpentier AC, Gagnon C, Menard J, Baillargeon JP, Ardilouze JL, et al. Reproducibility of the 6-minute walk test in obese adults. Int J Sports Med. 2009;30(10):725-7.

16. WHO. Physical status: the use and interpretation of anthropometry. Report of a WHO Expert Committee. World Health Organ Tech Rep Ser 1995;854:1-452

17. Malachias MV, Gomes MA, Nobre F, Alessi A, Feitosa AD, Coelho EB. 7th Brazilian Guideline of Arterial Hypertension. Arq Bras Cardiol . 2016 Sep;107(3 Suppl 3):7-13.

18. Borg GA. Psychophysical bases of perceived exertion. Med Sci Sports Exerc. 1982;14(5):377-81.

19. WHO. Obesity: Preventing and Managing the Global Epidemic. Report of a WHO Consultation. World Health Organ Tech Rep Ser . 2000;894:i-xii, $1-253$.

20. Lumley T, Diehr P, Emerson S, Chen L. The Importance of the Normality Assumption in Large Public Health Data Sets. Annu Rev Public Health. 2002;23(1):151-69.

21. Hulens M, Vansant G, Claessens AL, Lysens R, Muls E. Predictors of 6-minute walk test results in lean, obese and morbidly obese women. Scand J Med Sci Sports. 2003;13(2):98-105. 
22. Arena R, Myers J, Williams MA, Gulati M, Kligfield P, Balady GJ, et al. Assessment of Functional Capacity in Clinical and Research Settings. A Scientific Statement From the American Heart Association Committee on Exercise, Rehabilitation, and Prevention of the Council on Clinical Cardiology and the Council on Cardiovascular Nursing. Circulation. 2007;116(3):329-43.

23. Troosters T, Gosselink R, Decramer M. Six minute walking distance in healthy elderly subjects. Eur Respir J. 1999;14(2):270-4.
24. Chetta A, Zanini A, Pisi G, Aiello M, Tzani P, Neri M, et al. Reference values for the 6-min walk test in healthy subjects $20-50$ years old. Respir Med. 2006;100(9):1573-8.

25. Donini LM, Poggiogalle E, Migliaccio S, Pinto A, Lubrano C, Lenzi A. Sarcopenic Obesity: Correlation with Clinical, Functional, and Psychological Status in a Rehabilitation Setting. Food and Nutrition Sciences. 2014;Vol.05No.20:12

26. Maniscalco M, Zedda A, Giardiello C, Faraone S, Cerbone M, Cristiano $\mathrm{S}$, et al. Effect of Bariatric Surgery on the Six-Minute Walk Test in Severe Uncomplicated Obesity. Obesity Surgery. 2006;16(7):836-41. 